\title{
Breast Cancer-Related Apps in Google Play and App Store: Evaluate of Their Functionality and Quality
}

Aydanur AYDIN ( $\square$ aydanuraydin_88@hotmail.com )

Gümüşhane University https://orcid.org/0000-0001-5594-404X

Ayla GÜRSOY

Antalya Bilim University

\section{Research Article}

Keywords: mHealth, mobile health, mobile apps, store analysis, breast cancer

Posted Date: May 24th, 2021

DOl: https://doi.org/10.21203/rs.3.rs-448075/v1

License: (9) This work is licensed under a Creative Commons Attribution 4.0 International License.

Read Full License 


\section{Abstract}

Aim: This study aimed to evaluate the functionality and quality of breast cancer-related apps which can be accessed from Turkey.

Methods: The research covers 707 mobile applications, which were searched using the keywords "cancer", "oncology" and "breast cancer" in Google and App store stores between January and June 2019. The quality of apps was assessed with the user version of the Mobile App Rating Scale (MARS).

Results: Mobile applications focus on communication, education and treatment order / plan categories. The average MARS quality score for applications in all of the two stores was determined as 3.42. According to the average score of the scale sub-dimensions; It was seen that they were ranked as functionality, aesthetics, information quality and participation. MARS scale sub-groups were listed as functionality, aesthetics, knowledge quality, and participation.

Conclusion: e-Health is a subject that has just started to be used actively in health. Although basic information about breast cancer was used, information on prevention, early diagnosis and precautions was relatively limited and was not personalized. Support from healthcare professionals and further efforts should be made to develop evidence-based breast cancer knowledge and innovative technology and applications regarding cancer.

Implications for practice: e-Health technologies are a good tool in breast cancer, but appear to lack evidence-based content and individual specific areas such as age and education level.

\section{Introduction}

The use of technology in healthcare is preferred as a powerful method for maintaining patient follow-up, care and information (Fernandes et al., 2013; Lyles, López, Pasick, \& Sarkar, 2013). The development of technology in mobile devices is reflected in health services, and many medical mobile applications (apps) that contain information about health are easily installed on phones (Önder, Narin, Landau, \& Kandel, 2013). These applications are generally used by healthy people to gain awareness, and even provide nutritional and exercise advice in daily life. In addition, the ministry of health ensures that the health service is supported by technological tools by making the physician appointment system available to the public through the phone application. In a study, it is pointed out that easy access to mobile applications by everyone will make positive contributions to the maintenance of health services (Krebs \& Duncan, 2015). In another study, it is stated that the use of mobile applications in healthcare has increased at a level acceptable to the society (Stoyanov et al., 2015). Based on this information; It is thought that the mobile application can be a useful tool in managing the problems that may occur in a non-clinical environment, ensuring their participation in their care and receiving consultancy services.

In recent years, individuals have access to information and prefer internet and smart phone applications rather than printed media such as brochures and books. These applications facilitate access to 
information, as well as interesting, increasing reading and practice (Sert, 2012). In a study conducted with patients with breast cancer, it was observed that the mobile application developed to report symptoms and to cooperate with the hospital contributed positively to the acceptance and process of the disease in patients (Egbring et al., 2016). Patients experience postoperative problems and training methods such as brochures, consultancy and booklets are used in addition to verbal expression to cope with these problems (Lee et al., 2014; Ryhanen, Siekkinen, Rankinen, Korvenranta, \& Leino-Kilpi, 2010). It is reported that after the trainings, women frequently used the internet (22.5-45\%) to obtain information after breast cancer surgery (Muhamad, Afshari, \& Mohamed, 2011; Valero-Aguilera et al., 2014). Based on this information, bringing evidence-based information together with the ease of use of mobile applications to the service of the society will be one of the most important services that can be provided to these individuals. There are many websites on breast cancer organized by different individuals or institutions. However, studies investigating the functions and quality of existing sites are limited. This study aims to determine the intended use and quality of breast cancer applications available in the Google play store and app store.

\section{Methods}

First author searched English and Turkish app about BC from January 2018 to 2019. All of the app in the App store and Google play store about BC within the defined time horizon were included in the study.

\section{Search Strategy}

This review was completed using the Primary Reporting Items for Systematic Reviews and Metaanalyses (PRISMA) Guidelines. In the selection of mobile applications, applications related to different ORL subspecialties were searched in both the Google Play Store and the Apple App Store. The sub-specialties screened are "medicine", "health fitness" and "reference". The keywords used are "cancer / cancer", "oncology / oncology", "breast cancer / breast cancer" and "breast / breast". In total, 1683 English or Turkish apps were included.

\section{App Selection Process}

In the first search, data for each application was categorized according to the application name and version number, the cost of the application (if applicable) and the presence of in-app purchases. Applications were deemed eligible to be included in this review if they were in Turkish / English, were free (including or not included in-app purchases), were designed for breast cancer, and contain information about early diagnosis or treatment. The included apps have been downloaded to the Apple iphone X and Samsung Galaxy S5. Practices dealing with early diagnosis methods, treatment options and cancer prevalence related to breast cancer were included in the study. Applications not related to the scope of the study, applications promoting a business or individual, applications requiring hardware purchase, and applications in languages other than Turkish / English were excluded from the study. A total of 707 apps were included which in 356 Google play store and 351 App store (Fig. 1). 


\section{App Extraction}

First author (AA) downloaded the apps and critically evaluated the selected apps by a checklist. Because of the wide variation in the included apps, an Excel sheet was designed for data extraction. The first part of datasheet was general information about the app and publication year. The second part included number of downloads, user rating, number of reviews, available for free, and developer ID. Finally, the third part of it composed of $\mathrm{BC}$ early diagnosis methods, treatment options and cancer prevalence. We extracted the following data: developer, user rating, available for free, $\mathrm{BC}$ education, $\mathrm{BC}$ treatment, and $\mathrm{BC}$ communication.

\section{Quality Assessment}

The "Mobile Application Rating Scale" (MARS) scale was used to evaluate the quality of mobile applications in the stores. Developed by Stoyanov et al., The MARS measurement tool evaluates the qualities of the application in four sub-categories: (1) Participation (entertainment, interest, customization, interaction and target group), (2) Functionality (performance, ease of use, navigation, gestural design), (3) Aesthetics (layout, graphics, visual appeal) and (4) Information quality (accuracy of application description, objectives, quality and quantity of information, visual information, reliability, evidence base). Each item is evaluated on a 5-point Likert (1-Poor, 2-Poor, 3-Acceptable, 4-Good, 5-

Excellent) scale. Overall quality score; It consists of the mean scores of the interaction, functionality, aesthetics and information quality subscales. Each application was evaluated with the MARS scale independently by two authors. If the authors gave different points to the same application, the average of the two authors' scores was accepted as the MARS scale score for that application. MARS score was given with standard deviation (SD) and 95\% confidence interval (Cl).

\section{Results}

Characteristics of the Selected Apps

All applications were classified according to "education", "treatment order / plan" and "communication" sub-specialties. It was determined that 268 applications were used for education, 76 for treatment and 12 for communication purposes in the Google play store. In the app store, it was determined that there were 235 applications for education, 102 for treatment plan and order, and 14 applications for communication purposes. Of the applications in both stores, 270 (38.2\%) required internet for content access and 120 (17.1\%) required in-app purchases. Some of the applications (36.2\%) had more than 10 users' ratings for the current application version ( $n=269,38.1 \%$ ) and this rating was above 3 (max: 5 ). It was seen that the number of applications (361/707) that received four or more stars from the user ratings constituted $51 \%$ of the total (Table 1). 
Table 1

Characteristics of the breast cancer-related mobile apps.

\begin{tabular}{|c|c|c|}
\hline Characteristics & $\begin{array}{l}\text { App store }(n=351) \\
n(\%)\end{array}$ & $\begin{array}{l}\text { Google play store }(n=356) \\
n(\%)\end{array}$ \\
\hline Education & $235(66.9)$ & $268(75.2)$ \\
\hline Cancer information & $53(22.7)$ & $88(39.0)$ \\
\hline Guide & $72(30.6)$ & $53(19.7)$ \\
\hline Lecture notes & $64(27.2)$ & $55(20.5)$ \\
\hline Scientific journals & $46(19.5)$ & $56(20.8)$ \\
\hline Treatment & $102(29.1)$ & $76(21.3)$ \\
\hline Breast cancer symptoms & $31(30.3)$ & $22(28.9)$ \\
\hline Laboratory values & $26(25.5)$ & $21(27.6)$ \\
\hline Nutrition in cancer & $24(23.7)$ & $15(19.9)$ \\
\hline Drug use & $21(20.5)$ & $18(23.6)$ \\
\hline Communication & $14(4.0)$ & $12(3.5)$ \\
\hline Radiotherapy session follow-up & $8(57.1)$ & $9(75.0)$ \\
\hline Patient-physician follow-up & $6(42.9)$ & $3(25.0)$ \\
\hline \multicolumn{3}{|l|}{ Developer } \\
\hline Corporation & $251(57.3)$ & $203(57.1)$ \\
\hline Individual developer & $150(42.7)$ & $153(42.9)$ \\
\hline \multicolumn{3}{|l|}{ User rating (stars) } \\
\hline 0 & $4(1.1)$ & $1(0.2)$ \\
\hline 1 & $10(2.8)$ & $11(3.1))$ \\
\hline 2 & $13(3.7)$ & $14(3.9)$ \\
\hline 3 & $25(7.1)$ & $28(7.8)$ \\
\hline 4 & $91(25.9)$ & $92(25.8)$ \\
\hline 5 & $89(25.4)$ & $89(25.0)$ \\
\hline Missing & $119(34.0)$ & $121(34.2)$ \\
\hline
\end{tabular}




\begin{tabular}{|lll|}
\hline Characteristics & App store $(\mathbf{n}=351)$ & Google play store $(\mathbf{n}=356)$ \\
& $\mathbf{n}(\%)$ & $\mathbf{n}(\%)$ \\
\hline Yes & $331(94.3)$ & $339(95.2)$ \\
No & $20(5.7)$ & $17(4.8)$ \\
\hline
\end{tabular}

Quality of the Breast Cancer-Related Apps (uMARS Score)

According to the MARS scale score, it was found that approximately 75\% (525/707) of the applications related to breast cancer got four or more points (Min: 0, Max: 5). It was determined that the highest score was 4.4 and 227 (32.1\%) applications received full points (5). It was found that most of the applications were scored between three and four points (Fig. 2). The average overall MARS quality score (average score of four subscales) in applications in all two stores was determined to be $3.42 \pm 0.68$ (Cl: $3.58-3.72)$. Scale sub-dimensions were listed as functionality $4.05 \pm 0.57$, aesthetics $3.70 \pm 0.7$, knowledge quality $3.23 \pm 0.74$, and participation $2.34 \pm 0.56$. Education applications 3.65 (SD: $0.31 ; \mathrm{Cl}: 3.57-3.95$ ) average scores are 3.31 (SD 0.16; Cl: 3.53-3.73) higher than the average score of communication applications was determined to be.

\section{Discussion}

The research includes a comprehensive review of the functionality and quality of breast cancer-related applications available from phone stores. The results of the study include the results of evaluating the applications with a valid and reliable measurement tool that measures these properties. Applications in education category; information on the cancer process, a guide, lecture notes and a scientific journal. Applications in the treatment category; It was determined that it contained information about symptoms, laboratory values, nutrition and medications. It was observed that those in contact were of the type to be used for radiotherapy sessions and patient-physician communication. The results of the research could not be compared, since no similar research was available on breast cancer.

It was determined that the images of 18 applications containing information on early diagnosis methods in breast cancer were at a level that could be accessed from any search engine and the applications were not supported by video. In other studies that conduct mobile application reviews, it is pointed out that application contents lack evidence-based information and that content visuals should be enriched (Azar et al., 2013; Cowan et al., 2013; Wearing, Nollen, Befort, Davis, \& Agemy, 2014). In another study, it is pointed out that there is no standard in the creation of health-related mobile application content, but it is emphasized that only the modification of the contents by application developers creates a limitation (Hughson, Daly, Woodward-Kron, Hajek, \& Story, 2018). With this situation, it is pointed out that it is possible to access non-evidence based, incomplete or even incorrect information with mobile applications (Tripp et al., 2014). It can be said that the mobile application contents are in line with other research data and that the application contents are evaluated by experts and presented to the users in the stores will contribute to coping with these problems. 
It was found that the applications in the study were of medium quality and the highest score from the MARS assessment tool sub-dimensions was functionality. This result shows that the programs offer ease of use, performance and navigation opportunities by the users and it is a very important feature for an application. In a study evaluating applications with a similar measurement tool in Australia, it was noted that the quality of weight management and health practices for children / adolescents was higher in functionality sub-dimension scores than others (Bardus, van Beurden, Smith, \& Abraham, 2016). In a study examining pregnancy practices with a similar measurement tool, it was found that functionality scores higher in MARS sub-dimensions than others (Brown, Bucher, Collins, \& Rollo, 2019). The lowest score of the information quality among other sub-dimensions of the MARS measurement tool is also similar to other studies (Bardus et al., 2016; Brown et al., 2019). In addition to these, it was observed in the study that the participation score was lower than the other sub-dimensions. He states that this situation is insufficient in terms of entertainment, interest, customization and interaction features of mobile application contents and needs to be improved. It is seen that the features and effects offered to users by mobile applications produced in different cultures and languages are similar. In this context, it can be said that the features of mobile applications that need to be developed in the world are similar.

Mobile applications offer an extraordinary opportunity for patient follow-up, information and behavioral change in the field of health due to their easy accessibility and high usability (Bastl, Kmenta, Berger, \& Berger, 2018). When mobile application contents are equipped with high evidence level information, they can turn into an effective educational material. With the widespread use of mobile applications to be developed by healthcare professionals, the transfer of correct information will be easier (Stoyanov et al., 2015). In addition, it is the first research in our country that includes the systematic process carried out to select applications and the use of the MARS measurement tool to evaluate the quality of its applications.

\section{Implications for Nursing}

The applications available in the stores can be used in patient follow-up in the relevant clinics, patientnurse interaction and patient education.

Nurses' patient follow-up needs to be improved. The care service supported by technological products attracts more attention and provides more active participation by patients.

\section{Conclusion}

It is inevitable that mobile health applications will become widespread due to the advantages offered to patients and healthcare personnel. However, a healthcare professional should be involved in the creation of the application contents and the contents should be created by obtaining expert opinion. It seems that good evaluation is required to achieve this goal and there is no standard for academic approval.

Examining previous applications in the formation stages of an application, determining the strengths and weaknesses in terms of both content and design will make a significant contribution to the researcher. 
There is a need for more researchers working in this field and applications prepared with the support of healthcare professionals for different patient groups.

\section{Limitation}

Firstly, unlike many analyses based on app markets, we did not account for download counts or user ratings (which could be used as indicators of app popularity). Our priority was to assess breast cancer and market-related functionalities in order to inform future app development; therefore, all apps related to breast cancer that were relatively active were included. Secondly, even though the uMARS has been validated with mHealth apps, its application to cancer-related apps has yet to be validated, especially regarding the quality of the breast cancer information.

\section{Declarations}

\section{Funding}

The author declared that this study has received no financial support.

\section{Conflict of Interest}

None of the authors or affiliated institutions associated with this manuscript submission has any financial or personal relationship or affiliation that could influence the present work.

\section{Acknowledgements}

The author would like to thank all the participants in this study.

\section{Availability of data and material}

Not applicable

\section{Code availability}

Not applicable

\section{Authors' contributions}

Study conception and design, A. A, Data collection, A. A,

Data analysis and interpretation, A. A, A. G. Drafting of the article, A. A, A. G.

Critical revision of the article, A. A, A. G.

\section{Ethics approval:}

Not applicable 


\section{Consent to participate:}

Not applicable

\section{Consent for publication:}

Not applicable

\section{References}

1. Azar KM, Lesser LI, Laing BY, Stephens J, Aurora MS, Burke LE, Palaniappan LP (2013) Mobile applications for weight management: theory-based content analysis. Am J Prev Med 45(5):583-589

2. Bardus M, van Beurden SB, Smith JR, Abraham C (2016) A review and content analysis of engagement, functionality, aesthetics, information quality, and change techniques in the most popular commercial apps for weight management. International Journal of Behavioral Nutrition Physical Activity 13(1):1-9

3. Bastl K, Kmenta M, Berger M, Berger U (2018) The connection of pollen concentrations and crowdsourced symptom data: new insights from daily and seasonal symptom load index data from 2013 to 2017 in Vienna. World Allergy Organization Journal 11(1):1-8

4. Brown HM, Bucher T, Collins CE, Rollo ME (2019) A review of pregnancy apps freely available in the Google Play Store. Health Promotion Journal of Australia

5. Cowan LT, Van Wagenen SA, Brown BA, Hedin RJ, Seino-Stephan Y, Hall PC, West JH (2013) Apps of steel: are exercise apps providing consumers with realistic expectations? A content analysis of exercise apps for presence of behavior change theory. Health Education Behavior 40(2):133-139

6. Egbring M, Far E, Roos M, Dietrich M, Brauchbar M, Kullak-Ublick G, Trojan A (2016) A mobile app to stabilize daily functional activity of breast cancer patients in collaboration with the physician: $A$ randomized controlled clinical trial. J Med Internet Res 18(9):238

7. Fernandes A, Barros L, Barreira L, Joao C, Antonio A, Oliveira M,.. . Ferreira I (2013) Effects of different processing technologies on chemical and antioxidant parameters of Macrolepiota procera wild mushroom. LWT-Food Science Technology 54(2):493-499

8. Hughson J-aP, Daly JO, Woodward-Kron R, Hajek J, Story D (2018) The rise of pregnancy apps and the implications for culturally and linguistically diverse women: narrative review. JMIR mHealth uHealth 6(11):e189

9. Krebs P, Duncan D (2015) Health app use among US mobile phone owners: a national survey. JMIR mHealth uHealth 3(4):101

10. Lee MK, Yun YH, Park HA, Lee ES, Jung KH, Noh DY (2014) Web-based self-management exercise and diet intervention for breast cancer survivors: pilot randomized controlled trial. International Journal of Nursing Studies, 51(12), 1557-1567. Retrieved from https://www.ncbi.nlm.nih.gov/pubmed/24856854 
11. Lyles CR, López A, Pasick R, Sarkar U (2013) " 5 mins of uncomfyness is better than dealing with cancer 4 a lifetime": an exploratory qualitative analysis of cervical and breast cancer screening dialogue on Twitter. J Cancer Educ 28(1):127-133

12. Muhamad M, Afshari M, Mohamed NA (2011) Internet use and breast cancer survivors. The Turkish Online Journal of Educational Technology 10(4):241-247

13. Önder M, Narin B, Landau DVLM, Kandel A (2013) Akıllı telefonlar ve mobil uygulamaların (Apps) dermatolojide kullanımı. Archives of the Turkish Dermatology Venerology 47(1):1-6

14. Ryhanen AM, Siekkinen M, Rankinen S, Korvenranta H, Leino-Kilpi H (2010) The effects of Internet or interactive computer-based patient education in the field of breast cancer: a systematic literature review. Patient Educ Couns 79(1):5-13. doi:10.1016/j.pec.2009.08.005

15. Sert A (2012) Cep telefonu kullanıcılarının mobil reklamlara karşı tutumlarını etkileyen faktörler üzerine bir araştırma. (Yüksek Lisans Tezi Yüksek Lisans Tezi). İstanbul Arel Üniversitesi, İstanbul

16. Stoyanov SR, Hides L, Kavanagh DJ, Zelenko O, Tjondronegoro D, Mani M (2015) Mobile app rating scale: a new tool for assessing the quality of health mobile apps. JMIR mHealth uHealth 3(1):e27

17. Tripp N, Hainey K, Liu A, Poulton A, Peek M, Kim J, Nanan R (2014) An emerging model of maternity care: smartphone, midwife, doctor? Women Birth 27(1):64-67

18. Valero-Aguilera B, Bermudez-Tamayo C, Garcia-Gutierrez JF, Jimenez-Pernett J, Cozar-Olmo JM, Guerrero-Tejada R, Alba-Ruiz R (2014) Information needs and Internet use in urological and breast cancer patients. Support Care Cancer 22(2):545-552. doi:10.1007/s00520-013-2009-y

19. Wearing JR, Nollen N, Befort C, Davis AM, Agemy CK (2014) iPhone app adherence to expertrecommended guidelines for pediatric obesity prevention. Childhood Obesity 10(2):132-144

20. Stoyanov SR, Hides L, Kavanagh DJ, Zelenko O, Tjondronegoro D, Mani M. Mobile app rating scale: a new tool for assessing the quality of health mobile apps. JMIR Mhealth Uhealth $2015 \mathrm{Mar}$ 11;3(1):e27 [FREE Full text] [doi: 10.2196/mhealth.3422] [Medline: 25760773]

\section{Figures}




\section{Apps \\ (846 Android and 837 iOSApps)}

-537 Apps excluded:

- 68 Apps not in Turkish/English

- 469 duplicate Apps

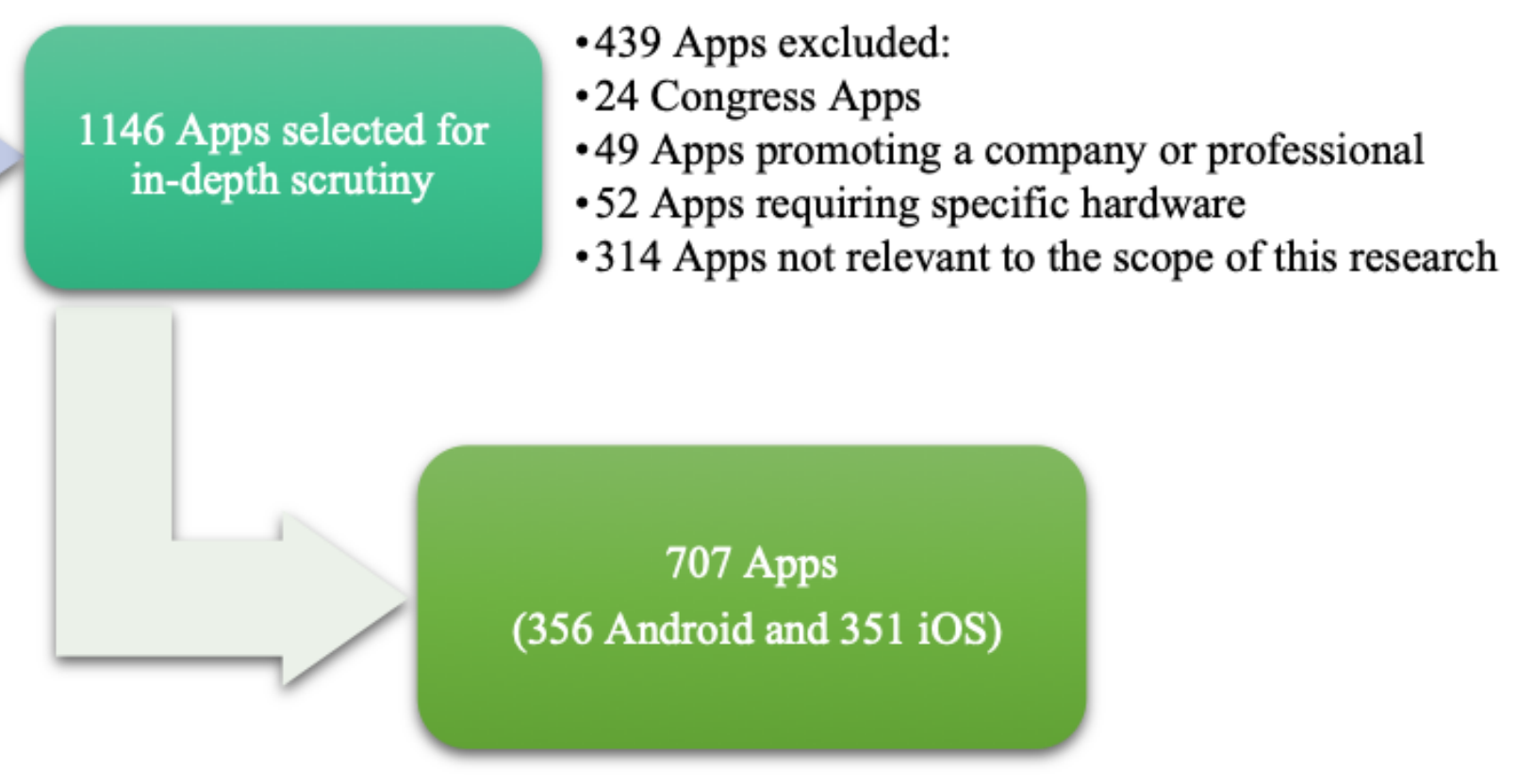

\section{Figure 1}

Primary reporting items for systematic reviews and meta-analyses (PRISMA) flowchart for apps selection.

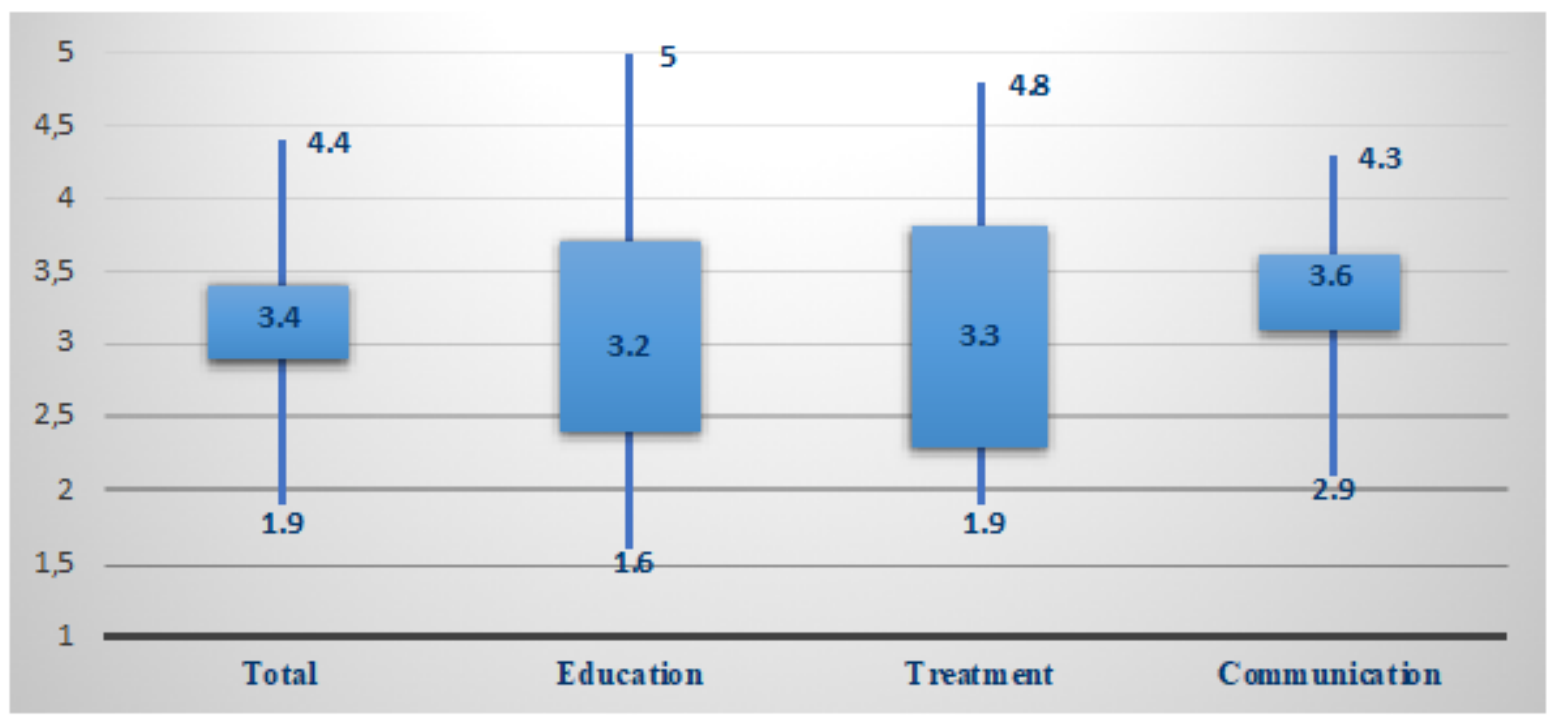

Figure 2

The user version of the Mobile App Rating Scale overall and section-specific scores of the breast cancerrelated apps $(n=707)$. Note: The bottom and top edge of the boxes represent the first and third quartiles; 
the lines within the boxes represent the medians and the ends of the bottom and top whiskers represent the minimum and maximum values. 